\title{
PATTERN OF LYMPH NODE METASTASIS IN ORAL CANCER
}

\author{
RIFAT MA ${ }^{1}$, AREFIN MK ${ }^{2}$, FAKIR AY ${ }^{3}$, RUMI SNF ${ }^{4}$, OSMANY HQ ${ }^{5}$, ROKTIM HR ${ }^{6}$, MOSTAFA \\ $\mathrm{T}^{7}$, HOSSAIN MZ ${ }^{8}$, CHOWDHURY PP 9
}

\begin{abstract}
Background: Oral cancer is a common neoplasm worldwide which has a increased incidence and mortality rate over the past decades. In spite of skilled surgical and radio therapeutic modalities it is characterized by poor prognosis and a low survival rate. Lymph node metastasis is an important negative prognostic factor in oral cancer. In this study, pattern of cervical lymph node metastasis in oral carcinoma has been described. Such information may contribute to the understanding of oral cancer management plan.
\end{abstract}

Methods: This cross-sectional observational study was conducted in the Otolaryngology and Head-Neck surgery department of Dhaka Medical College Hospital. The study period was from January 2018 to June 2018. A total of 50 patients were selected by purposive sampling technique. Data were collected by study physician himself. Then these collected data were recorded in structured case report forms. Clinical examination and relevant investigations were done. After planned surgical procedure post operative histopathological reports were collected. All collected questionnaire were checked very carefully. Data were processed and analyzed with the help of computer program SPSS and Microsoft excel. Quantitative data were expressed as mean and standard deviation and qualitative data as frequency and percentage. Comparison were done by tabulation and graphical presentation in the form of tables, pie chart, graphs, bar diagrams, histogram \& charts etc.

Result: Overall demographic features of 50 patients revealed that, the maximum incidence was seen in the age group 31-50 years (54.0\%), mean age of the patient was $49.6 \pm 9.2$ year. Male and female ratio was 4.5:1. In this study most of the tumors were well and moderately differentiated, 34.0\% and 62.0\% respectively. Aetiology and predisposing factors revealed that the most common were cigarette smoking, betal quid and alcohol consumption, present in $52.0 \%$, $28.0 \%$ and $22.0 \%$ of patients respectively. Post operative histopathology reports showed that 24 patients (48.0\%) had neck node metastasis among which $59.4 \%$ were with tumor size $>1 \mathrm{~cm}$. Tumors with the depth of invasion $>3 \mathrm{~mm}$ had a very high risk of metastasis $(P<0.0001)$, as compared to tumor less than $3 \mathrm{~mm}$ in thickness. Out of the 24 patients with nodal metastasis 17(34.0\%) patients had a single node metastasis (N1). Level I and Level II were the commonest site to be involved (14 patients). Nodal metastasis predominantly occurred from primary tumour site of tongue (22.0\%) and floor of the mouth (14.0\%).

It was seen that patients with higher grade had a higher risk of metastasis (grade 1:-29.4\%, grade 2:- $54.8 \%$, grade 3:- $100.0 \%)$.

Conclusion: Oral carcinoma may appear at any sub site, although there are certain areas in which it is found more frequently, such as the oral tongue, cheek and floor of the mouth. Lymph node metastasis is more common in oral carcinoma mostly level I \& II, which is one of the most relevant prognostic factors. Elective neck dissection can be considered in all patients with tumors more than $3 \mathrm{~mm}$ in thickness.

Key words: Oral cancer, squamous cell carcinoma, nodal metastasis

DOI: https://doi.org/10.3329/jdmc.v29i1.51170

J Dhaka Med Coll. 2020; 29(1) : 41-46

1. Dr. Mahmud Asif Rifat, Indoor Medical Officer, Dept. of ENT \& Head-neck Surgery, Dhaka Medical College Hospital, Dhaka

2. Dr. Mostafa Kamal Arefin, Indoor Medical Officer, Dept. of ENT \& Head-neck Surgery, Dhaka Medical College Hospital, Dhaka

3. Dr. Abu Yusuf Fakir, Professor \& ADG, Directorate General of Health service, Mohakhali, Dhaka

4. Dr. SK Nurul Fattah Rumi, Professor \& Head of the Department of ENT \& Head-neck Surgery, Dhaka Medical College, Dhaka

5. Dr. Husne Qumer Osmany, Associate Professor, Dept. of ENT \& Head-neck Surgery, Dhaka Medical College, Dhaka

6. Dr. Hashim Reza Roctim, MS resident, Dept. of ENT \& Head-neck Surgery, Dhaka Medical College Hospital, Dhaka

7. Dr. Tanvir Mostafa, MD, Resident, Dhaka Medical College, Dhaka

8. Dr. Mohammad Zaid Hossain, Associate Professor of Medicine, Dhaka Medical College, Dhaka

9. Dr. Partha Pratim Chowdhury, Assistant Professor of Medicine, Dhaka Medical College, Dhaka

Correspondence: Dr. Mahmud Asif Rifat, Indoor Medical Officer, Dept. of ENT \& Head-neck Surgery, Dhaka Medical College Hospital, Dhaka, Email: rifat62ent@gmail.com

Received: 06-01-2020

Revision: 17-01-2020

Accepted: 21-03-2020 


\section{Introduction}

Oral cancer is one of the highly prevalent cancer worldwide. In South-Central Asia it is a leading cause of mortality. Increased life expectancy and lifestyle changes have all contributed to increase the rate of oral cancer in the world. It is highly prevalent in South Asian countries like India, Bangladesh, Pakistan and Sri Lanka, where one-third of all the cancers reported are oral cancer ${ }^{1}$. According to GLOBOCAN 2012, around $16,88,50$ new cases of lip and oral cavity cancer were diagnosed and was the 12 th most common cancer in Asia. In South-Central Asia it is the second most common cancer among men, with an age-standardized incidence of 9.9 and a 5year prevalence of $129,057(12.1 \%)^{2}$.

Patients with small lesion are often asymptomatic. Sometimes they may present with vague symptoms and minimal physical findings. In such cases, where the patients have tobacco and alcohol habits, a high index of clinical suspicion is needed to diagnose. In patients with upper digestive tract SCC neck lymph nodes are the first site affected by metastases usually. Presence of metastasis is one of the most relevant prognostic factors for patients with oral $\mathrm{SCC}^{4}$. Study reported that oral tongue carcinoma has a higher risk of metastasis to the regional lymph nodes where level I (50\%) and level II (75\%) were commonly involved. In buccal SCC level I (99.98\%) and level II (83.33\%) were also commonly involved neck levels. Cervical metastasis was absent in lip and alveolar $\mathrm{SCC}^{5}$. On univariete analysis the risk factors associated with the lymph node metastasis are the tumor size, tumor grade and the tumor thickness. It is seen that patient with higher grade has a higher risk of metastasis ${ }^{6}$.

Cervical neck node metastasis in oral SCC does occur initially on levels I to III. On more progression they can also reach level IV and $\mathrm{V}^{4}$. This study was aimed to analyze the pattern of lymph node metastasis in oral carcinoma patient.

\section{Methodology}

In this cross-sectional study, 50 diagnosed cases of oral squamous cell carcinoma admitted at DMCH from January 2018 to June 2018 were enrolled randomly. The cases were seen by the study physician and briefed about the objectives of the study, risk, benefits, freedom for participating in the study and confidentiality. Informed consents were obtained accordingly. After fulfilling the inclusion (diagnosed squamous cell carcinoma) and exclusion criteria (Carcinoma base of tongue $\& /$ or oropharynx) patients were enrolled with unique ID. Relevant information regarding patient's history and clinical findings were recorded. Basic hematological and other relevant investigations (including USG of neck with guided FNAC, CT scan of neck- where applicable) were done. Surgery of the primary and neck were performed in all these cases. Post operative histopathological reports were collected. Patient's data such as age, sex, clinical presentation, examination and investigation findings, post operative histopathological reports etc were noted in the pre-structured Case Record Form (CRF) by the study physician himself. All the collected data were checked very carefully and processed accordingly.

\section{Results}

\section{Table-I}

Demographic characteristics of the patients $(n=50)$

\begin{tabular}{lccc}
\hline Age (years) & \multicolumn{2}{c}{ Frequency } & Total \\
\cline { 2 - 3 } & Male $(n=41)$ & female $(n=9)$ & \\
\hline $16-30$ & $5(12.1 \%)$ & 0 & 5 \\
$31-50$ & $24(58.5 \%)$ & $3(33.4 \%)$ & 27 \\
$51-70$ & $9(21.9 \%)$ & $5(55.6 \%)$ & 14 \\
$>70$ & $3(7.3 \%)$ & $1(11.1 \%)$ & 4 \\
Mean $\pm \mathrm{SD}$ & $49.6 \pm 9.2$ & & \\
\hline
\end{tabular}

Overall demographic features of 50 patients are shown in Table 3.1. In this study, the maximum incidences were seen in the age group 31-50 years $(54.0 \%)$, next to it were age group 51-70 years $(28.0 \%)$. Mean age of the patient was 49.6 \pm 9.2 year. 
Table-II

Gender distribution of patients $(n=50)$

\begin{tabular}{lcc}
\hline Gender & Number of Patients & Percentage \\
\hline Male & 41 & 82.0 \\
Female & 9 & 18.0 \\
$M: F$ & & $4.5: 1$ \\
\hline
\end{tabular}

Figure shows gender of the patients. Out of 50 cases $41(82.0 \%)$ cases were male and $9(18.0 \%)$ were female. Male and female ratio was 4.5:1.

\section{Table- III}

Distribution of the patients according to primary tumour site $(n=50)$

\begin{tabular}{lcc}
\hline Location & Frequency & Percentage \\
\hline Tongue & 21 & 42.0 \\
Floor of the mouth & 13 & 26.0 \\
Buccal mucosa \& lower & 9 & 18.0 \\
gum & & \\
Retro molar trigone & 3 & 6.0 \\
Lip & 2 & 4.0 \\
Hard palate & 2 & 4.0 \\
\hline
\end{tabular}

Table shows the primary tumour site of oral carcinoma. It may appear in any location, although there are certain areas in which it is found more frequently, such as the tongue $(42.0 \%)$, floor of the mouth $(26.0 \%)$ and lower gum $(18.0 \%)$.

Table-IV

Aetiology and predisposing factors $(n=50)$

\begin{tabular}{lcc}
\hline Aetiology and & Frequency & Percentage \\
\hline predisposing factors & & \\
Cigarette smoking & 26 & 52.0 \\
Betel quid & 14 & 28.0 \\
Alcohol & 11 & 22.0 \\
Naswar & 3 & 6.0 \\
jagged shape teeth & 7 & 14.0 \\
Ill-fitting dentures & 6 & 12.0 \\
Poor oral hygiene & 18 & 36.0 \\
\hline
\end{tabular}

Aetiology and predisposing factors revealed that the most common was cigarette smoking, betal quid and alcohol consumption, present in $52.0 \%, 28.0 \%$ and $22.0 \%$ of patients respectively.

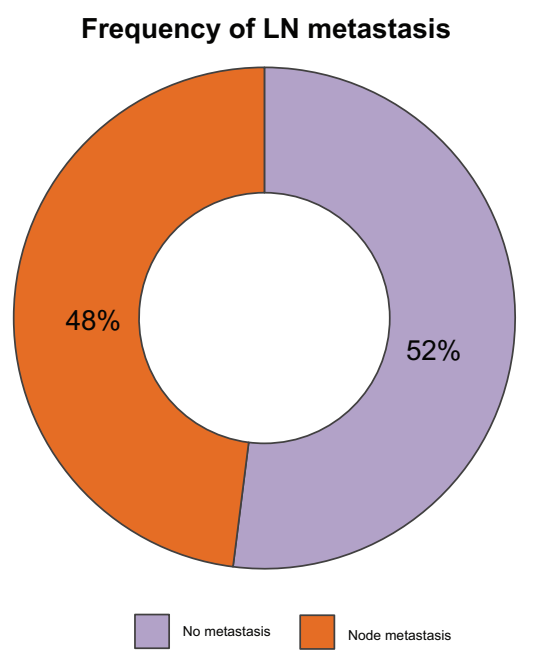

Fig.-5: Frequency of lymph node metastasis $(n=50)$

Present study demonstrated that, frequency of lymph node metastasis was $24(48.0 \%)$ in oral carcinoma patients with varying degree of lymph node involvement.

Table- V

Clinicopathological evaluation of node involvement $(n=50)$

\begin{tabular}{lcc}
\hline $\begin{array}{l}\text { Clinicopathological } \\
\text { characteristics } \\
\text { of LN }\end{array}$ & $\begin{array}{c}\text { Number of } \\
\text { patients }\end{array}$ & $\begin{array}{c}\text { Percentage } \\
(\%)\end{array}$ \\
\hline $\begin{array}{l}\text { Pathological node } \\
\text { involvement }\end{array}$ & & \\
PNO & 26 & $52.0 \%$ \\
PN1 & 17 & $34.0 \%$ \\
PN2 & 7 & $14.0 \%$ \\
Pathological node & & \\
distribution according & & \\
to neck levels & & \\
I & 8 & 16.0 \\
II & 6 & 12.0 \\
III & 4 & 8.0 \\
IV & 2 & 4.0 \\
II \& III & 3 & 6.0 \\
II, III \& IV & 1 & 2.0 \\
\hline
\end{tabular}


In this study $52.0 \%$ patients were NO after pathological examination and 24 patients $(48.0 \%)$ showed neck node metastasis. Out of the 24 patients with nodal metastasis, $17(34.0 \%)$ patients had a single node metastasis (N1). Level I and Level II were the commonest sites to be involved (14 patients). Four patients had metastasis at level III without level I or II involvements. Three patients had metastasis at level IV with single patient having skip metastasis at level IV.

\section{Table-V}

Node metastasis according to sub site $(n=50)$

\begin{tabular}{lcccc}
\hline \multirow{2}{*}{$\begin{array}{l}\text { Socation } \\
\text { Subsite }\end{array}$} & \multicolumn{3}{c}{ Frequency of node metastasis } & Total \\
\hline Tongue & 10 & 7 & 4 & 21 \\
Floor of the mouth & 6 & 5 & 2 & 13 \\
Buccal mucosa \& & 6 & 3 & 0 & 9 \\
lower gum & & & & \\
Retro molar trigone & 3 & 0 & 0 & 3 \\
Lip & 0 & 1 & 1 & 2 \\
Hard palate & 1 & 1 & 0 & 2 \\
\hline
\end{tabular}

Table shows the node metastasis according to subsite. Nodal metastasis predominantly occurred from primary tumour site of tongue $(22.0 \%)$ and floor of the mouth $(14.0 \%)$.

Table-VI

Univariate analysis of factors influencing the lymph node metastasis in oral cancer $(n=50)$

\begin{tabular}{lcccc}
\hline Variables & $\begin{array}{c}\text { Total number } \\
\text { of patients }(\mathrm{n}=50)\end{array}$ & $\begin{array}{c}\text { Number of patients } \\
\text { with }\end{array}$ & $\begin{array}{c}\text { Percentage } \\
(\%)\end{array}$ & positive $(\mathrm{n}=24)$ \\
\hline$<50$ year & 32 & 15 & 46.8 & 0.071 \\
$>50$ year & 18 & 9 & 50.0 & \\
Sex & 41 & 20 & 48.7 & 0.803 \\
Male & 9 & 4 & 44.5 & \\
Female & & & & \\
Grade & 17 & 5 & 29.4 & 0.0001 \\
Well & 31 & 17 & 54.8 & \\
Moderate & 2 & 2 & 100.0 & \\
Poor & & & & \\
Tumour size & 13 & 2 & 15.3 & \\
$<1$ cm & 37 & 22 & 59.4 & \\
$>1$ cm & & & 33.3 & 0.0001 \\
Thickness & 21 & 7 & 58.6 & \\
$<3$ mm & 29 & 17 & \\
$>3$ mm & & &
\end{tabular}

Table shows the different factors influencing the lymph node metastasis in oral SCC. Risk factors associated with the lymph node metastasis were the tumor size, tumor grade and the tumor thickness. Tumors were divided into size $<1 \mathrm{~cm}$ and size $>1 \mathrm{~cm}$. Maximum patients (e.g., 59.4\%) had tumor size $>1 \mathrm{~cm}$. Only $15.3 \%$ patient with tumor size less than $1 \mathrm{~cm}$ had lymph node metastasis. Patients with higher grade had a higher risk of metastasis (grade: 1-29.4\%, grade: $2-54.8 \%$, grade: $3-100.0 \%$ ). So grading is a significant risk factor for metastasis $(p=0.0001)$.Tumors with the depth of invasion $>3 \mathrm{~mm}$ had a very high risk of metastasis $(\mathrm{P}<0.0001)$, as compared to tumor less than 3 $\mathrm{mm}$ in thickness. Elderly age ( $>50$ year) was found having more lymph node metastasis in compared with age group $<50$ year, although it 
did not reach statistical significance $(\mathrm{P}=0.089)$.

\section{Discussion}

Overall demographic features of 50 patients has revealed that, the maximum incidences are seen in the age group $31-50$ years $(54.0 \%)$. Out of 50 cases $41(82.0 \%)$ are male and $9(18.0 \%)$ are female. Male and female ratio is 4.5:1. All findings are accordance with result of other studies. In some population groups oral cancer is more prevalent among men because of heavy tobacco and alcohol consumption among them ${ }^{1}$. Other study shows the age range of the patients from 22 to 75 years with a mean age of 52.6 years having male and female ratio $1.5: 1^{3}$.

On evaluation of primary tumour sites of oral carcinoma, there are certain areas where it has been found more frequently, such as the tongue $(42.0 \%)$, floor of the mouth $(26.0 \%)$ and buccal mucosa with lower gum (18.0\%). In Western countries oral SCC affects primarily the tongue and the floor of the mouth. Together these sites account for about $50 \%$ of all cases of oral SCC. Other sites are less frequently affected like gingivae, palate, retromolar area and the buccal and labial mucosa. ${ }^{7,8}$

In this study most of the tumors are well and moderately differentiated, $34.0 \%$ and $62.0 \%$ respectively. Aetiology and predisposing factors have revealed that the most common is cigarette smoking, betal quid and alcohol consumption, present in $52.0 \%, 28.0 \%$ and $22.0 \%$ of patients respectively. Well known risk factors for oral squamous cell carcinoma are use of tobacco and betel quid, heavy drinking of alcoholic beverages and a diet low in fresh fruits and vegetables. Large tumour size, regional lymph node metastasis and deep invasion of tumour at the time of diagnosis are associated with poor prognosis ${ }^{7}$. In South-central Asia, it is a common entity and the third most common type of cancer ${ }^{1}$.

Present study result has demonstrated that, frequency of lymph node metastasis is $48.0 \%$ in oral squamous cell carcinoma patients. In this study $52.0 \%$ patients were NO after pathological examination and 24 patients $(48.0 \%)$ showed neck node metastasis. Out of these 24 patients with nodal metastasis $17(34.0 \%)$ patients had single node metastasis (N1). Level I and Level II were the commonest sites to be involved (14 patients). Four patients had metastasis at level III without level I or II involvements. Three patients had metastasis at level IV with skip metastasis at level IV in single patient. Findings consistent with results of other studies. In a study, amongst the 57 patients, twenty two patients underwent MND1 and 35 patients underwent MND2. Thirty six $(63.15 \%)$ patients were NO after pathological examination and 21 patients $(36.85 \%)$ showed neck node metastasis. Out of the 21 patients with nodal metastasis 15 patients had a single node metastasis (N1). Either level I or level II was the commonest site to be involved (ten patients). Four patients had metastasis at level III without level I or II involvements ${ }^{6}$.

Present study has showed the different factors influencing the lymph node metastasis in oral cancer. The risk factors associated with lymph node metastasis were the tumor size, tumor grade and the tumor thickness. Maximum patients (e.g., 59.4\%) had tumor size $>1 \mathrm{~cm}$. Only $15.3 \%$ patient with tumor size less than 1 $\mathrm{cm}$ had lymph node metastasis making the tumor size a significant risk factor for metastasis $(p<0.0001)$. Patients with high grade tumour have a higher risk of metastasis (grade: $1-29.4 \%$, grade: $2-54.8 \%$, grade:3- $100.0 \%$ ). Tumors with the depth of invasion $>3 \mathrm{~mm}$ have a very high risk of metastasis $(\mathrm{P}<0.0001)$, as compared to tumor less than $3 \mathrm{~mm}$ in thickness.

In previous study it was seen that patients with higher grade had a higher risk of metastasis (grade $1-18.2 \%$, grade $2-46.9 \%$ and grade 3$66.7 \%)$ although it did not reach statistical significance $(\mathrm{P}=0.054)$. Tumors with the depth of invasion $>3 \mathrm{~mm}$ had a very high risk of metastasis $(\mathrm{P}<.0002)$, as compared to tumor less than $3 \mathrm{~mm}$ in thickness ${ }^{6}$. About two-third of oral SCC are already of substantial size, and will have clinically detectable metastasis to cervical lymph nodes at the time of diagnosis ${ }^{10,11}$. Importantly, in about $20 \%-40 \%$ of cases with no clinical or imaging evidence of metastatic spread to lymph nodes at the time of diagnosis of oral SCC, histopathological 
examination of the regional lymph nodes will show metastasis ${ }^{11}$. Squamous cell carcinoma of the lip, hard palate and maxillary gingiva infrequently metastasize to regional lymph nodes, usually run a relative indolent course and have a relatively favorable prognosis. But SCC of the tongue, floor of the mouth and mandibular gingiva often metastasize to regional lymphnodes and are more aggressive with a less favorable prognosis ${ }^{7}$. Small welldifferentiated, low-grade oral SCC usually metastasize to regional lymph nodes only after invading connective tissue, muscle or bone. On the other hand, poorly-differentiated, highgrade oral SCC is biologically more aggressive and tends to metastasize to regional lymph nodes early in the course of the disease ${ }^{9}$.

\section{Conclusion}

The lymph node metastasis is one of the strongest predictor of survival and outcome of oral carcinoma patients. Tongue cancer is well known for its early metastasis. For regional control of the disease treatment of neck along with the primary is the gold standard. The high incidence of neck metastasis in oral carcinoma, especially with poor grade, larger size $(>1 \mathrm{~cm})$ and thickness $(>3 \mathrm{~mm})$, the unreliability of clinical examination and adjunct investigations in detecting occult metastasis make elective treatment of the neck either by surgery or radiotherapy is very much necessary. We suggest that all the patients with oral SCC involving mainly the tongue, floor of the mouth and buccal mucosa with tumor thickness more than $3 \mathrm{~mm}$ should undergo at least a supraomohyoid neck dissection along with the primary on prophylactic basis.

\section{Conflict of interest:}

All authors declared, there is no conflict of interest.

\section{Contributions:}

Rifat MA prepared the manuscript and submitted. All other authors read, revised and participated in coordination of this article.

\section{Limitations of the study}

This study was not without limitation. The limitations of the studies were as follows:

- It was a short time. Only patients admitted at $\mathrm{DMCH}$ were taken for the study. So this will not reflect the overall picture of the country. A large scale study needs to be conducted to reach to a definitive conclusion

- Study was conducted in tertiary care hospital which may not represent the real scenario of the country.

- Sample were taken by purposive method in which question of personal biasness might arise.

- Relationship between HPV infection and oral cavity cancer cannot be determined

\section{References:}

1. Gupta N, Gupta R, Acharya A, Patthi B, Goud V, Reddy S, et al. Changing Trends in oral cancer - a global scenario. Nepal J Epidemiol. 2016; 6(4); 613619.

2. GLOBOCAN: Estimated Cancer Incidence, Mortality and Prevalence Worldwide in 2012. International Agency for Research on Cancer [online] 2012 [ cited 2018 July 16] Available from: URL: http:// globocan.iarc.fr/Pages/fact_sheets_population.aspx.

3. Nithya CS, Pandey M, Naik BR and Ahamed IM. Patterns of cervical metastasis from carcinoma of the oral tongue. World Journal of Surgical Oncology 2003, $1: 10$

4. Köhler H, Kowalski L. Prognostic impact of the level of neck metastasis in oral cancer patients. Braz J Otorhinolaryngology. 2012; 78(6):15-20.

5. Rahim D, Siddiqui A, Ahmed Z, Marfani M. Frequency of Cervical Metastasis in Oral Cancer. Pakistan Journal of Otolaryngology 2013; 29: 80-83.

6. Vishak S \&Rohan V. Cervical node metastasis in T1 squamous cell carcinoma of oral tongue- pattern and the predictive factors. Indian J SurgOncol, 2014; 5(2): 104-108.

7. Feller L and Lemmer J. Oral Squamous Cell Carcinoma: Epidemiology, Clinical Presentation and Treatment. Journal of Cancer Therapy, 2012; 3: 263268

8. S. Warnakulasuriya. Global Epidemiology of Oral and Oropharyngeal Cancer," Oral Oncology, Vol. 45, No. 4, 2009, pp. 309-316.

9. Shah JP and Gil Z. Current Concepts in Management of Oral Cancer-Surgery. Oral Oncology, 2009; Vol. 45, No. 4: 394-401

10. Neville BW and Day TA. Oral Cancer and Precancerous Lesions, CA:A Cancer Journal for Clinicians 2002; Vol. 52, No. 4: 195-215.

11. Massano J, Regateiro FS, Januario G and Ferreira A. Oral Squamous Cell Carcinoma: Review of Prognostic and Predictive Factors. Oral Surgery, Oral Medicine, Oral Pathology, Oral Radiology and Endodontics, 2006; Vol. 102, No. 1: 67-76. 